\title{
On the Relevance of Neuroscience to Criminal Responsibility
}

\author{
Nicole A Vincent
}

Published online: 26 November 2009

(C) The Author(s) 2009. This article is published with open access at Springerlink.com

\begin{abstract}
Various authors debate the question of whether neuroscience is relevant to criminal responsibility. However, a plethora of different techniques and technologies, each with their own abilities and drawbacks, lurks beneath the label "neuroscience"; and in criminal law responsibility is not a single, unitary and generic concept, but it is rather a syndrome of at least six different concepts. Consequently, there are at least six different responsibility questions that the criminal law asks-at least one for each responsibility concept — and, I will suggest, a multitude of ways in which the techniques and technologies that comprise neuroscience might help us to address those diverse questions. In a way, on my account neuroscience is relevant to criminal responsibility in many ways, but I hesitate to state my position like this because doing so obscures two points which I would rather highlight: one, neither neuroscience nor criminal responsibility are as unified as that; and two, the criminal law asks many different responsibility questions and not just one generic question.
\end{abstract}

Keywords Responsibility $\cdot$ Neuroscience $\cdot$ Criminal law $\cdot$ Neurolaw

\section{A Simple Question}

Is neuroscience relevant to criminal responsibility?

Some people think that it is relevant. For instance, Joshua Greene and Jonathan Cohen maintain that advances in neuroscience demonstrate that "[f]ree will... is an illusion" and so they contend that the criminal law's retributive aims should be replaced with such aims as deterrence, prevention and treatment (2004:224). Robert Sapolsky's discussion of the role that the frontal cortex plays in self-control is also a plea for "a world of criminal justice in which there is no blame [but] only prior causes" (2004:1794). Finally, Richard

\footnotetext{
N. A Vincent $(\bowtie)$

Philosophy Department, Faculty of TBM, Delft University of Technology, PO Box 5015, 2600 GA Delft, The Netherlands

e-mail: n.a.vincent@tudelft.nl
} 
Dawkins takes an even harder stance against what he sees as "the flawed concept of retributi[ve]" punishment-he argues that "as a moral principle [retribution] is incompatible with a scientific view of human behaviour" because on his account "a truly scientific, mechanistic view of the nervous system make[s] nonsense of the very idea of responsibility" - and so he too feels that the law's proper aims should be deterrence, prevention, treatment and perhaps removal of dangerous individuals from society, but certainly not retribution (2006). According to Greene, Cohen, Sapolsky and Dawkins, neuroscientific findings are highly relevant to criminal responsibility-i.e. they entail that the criminal law should be purged of its archaic retributive aspirations.

But others disagree. Stephen Morse "contends that neuroscience is largely irrelevant" to the criminal law's decisions concerning "responsibility ascriptions and just punishment" (2006:34) because, as he sees it, the law's responsibility practices are about norm-setting and not just about fact-finding. On his account, there is little that neuroscience can tell us about such things as just how careful a person must be to avoid being seen as having been insufficiently careful and thus as responsible for some accidental misfortune; or about whether the appropriate kind and degree of punishment for theft is a fine, incarceration, ten lashes of the whip, twenty lashes, amputation of the hand that stole the item, or execution of the offender. Similarly, Michael Gazzaniga contends that although the neuroscientist's "counsel is... often sought [in] the court of law" (2006:144) to determine the extent of an accused person's responsibility, he insists that neuroscientists should refrain from commenting on such matters because "responsibility, [is] a social construct that exists in the rules of a society, [and] not ... in the neuronal structures of the brain... In neuroscientific terms, no person is more or less responsible than any other [person] for [their] actions [because w]e are all part of a deterministic system that some day, in theory, we will completely understand" (2005:101-102). According to Morse and Gazzaniga neuroscience is not particularly relevant to criminal responsibility, and so on their accounts the neuroscience-inspired calls for legal reform should probably be ignored.

Various things could be said about these arguments. For instance, it is curious that Dawkins and Gazzaniga both cite the same sorts of considerations-a "mechanistic view of the nervous system" and that the brain is "a deterministic system", respectively-but yet that each supports the opposite side in this debate (i.e. Dawkins is pro-reform, whereas Gazzaniga is not). Or we could puzzle about why Greene and Cohen think that the law's retributive practices can only be defended under a libertarian theory which they find wanting, when Fischer and Ravizza's (1998) compatibilist theory could instead ground the law's retributive practices. And finally, we might wonder why Morse insists that neuroscience is largely irrelevant, when in fact the considerations which he cites suggest that neuroscience does have some relevance, albeit limited relevance. Never the less, I will put such puzzles aside because I believe that this way of putting the question-i.e. Is neuroscience relevant to criminal responsibility? - is problematic in at least three ways. ${ }^{1}$

\footnotetext{
1 Admittedly, from the above quotes only Morse's comments directly address this relevance question, and so I should explain why I frame the other authors' works as responses to this question too. Firstly, many authors in this field present their work as a response to Morse-for instance, at the recent UCL Law and Neuroscience Colloquium (2009) a number of prominent speakers explicitly presented their work as a response to what they called "the Morse challenge" —and so it is plausible that others' work may inherit some of the assumptions implicit in Morse's position. Secondly, as Egan (2007) notes, this was explicitly framed as a relevance question in Daubert v. Merrell Dow Pharmaceuticals (1993) where it was found that " $[\mathrm{t}$ ] he Rules [of Evidence] assign... to the trial judge the task of ensuring that an expert's testimony... is relevant to the task at hand" (emphasis added), and so either self-consciously or implicitly the philosophical literature in this area also addresses this relevance question.
} 
Firstly, it is not clear whether the relevance question asks whether current neuroscience is relevant to criminal responsibility, or whether future neuroscience might be relevant to criminal responsibility. This paper will concern itself with the latter question-i.e. with whether an ideal future neuroscience might be relevant to criminal responsibility-though where fitting examples of current neuroscience present themselves, I shall cite them for demonstrative purposes.

Secondly, this way of putting the question is also problematic because neither neuroscience nor criminal responsibility is sufficiently unified or homogenous to justify the expectation that an intelligible one-to-one relationship can be sought (let alone found) between one thing called "neuroscience" and another thing called "criminal responsibility". Regarding "neuroscience", the table below shows a number of different techniques and technologies all of which fit that name:

\begin{tabular}{|c|c|c|c|}
\hline & \multicolumn{2}{|c|}{$\begin{array}{c}\text { diagnostic } \\
\text { observation/reading }\end{array}$} & $\begin{array}{l}\text { intervention } \\
\text { alteration/writing }\end{array}$ \\
\hline psychopharmacology & \multicolumn{2}{|c|}{ blood chemistry analysis } & psychotropic drugs \\
\hline $\begin{array}{l}\text { invasive } \\
\text { techniques } \\
\text { (intracranial) }\end{array}$ & \multicolumn{2}{|c|}{ ECoG ElectroCorticoGram } & $\begin{array}{l}\text { DBS Deep Brain Stimulation } \\
\text { brain surgery }\end{array}$ \\
\hline $\begin{array}{l}\text { non-invasive } \\
\text { techniques } \\
\text { (transcranial) }\end{array}$ & \multicolumn{2}{|c|}{$\begin{array}{c}\text { EEG ElectroEncephaloGram } \\
\text { MEG MagnetoEncephaloGram } \\
\text { NIRS } \text { Near Infra-Red Spectroscopy }_{\text {TCDS }} \text { TransCranial Doppler Spectroscopy }\end{array}$} & $\begin{array}{c}\text { ECT ElectroConvulsive Therapy } \\
\text { TMS Transcranial Magnetic Stimulation }\end{array}$ \\
\hline radiology & structural & functional & \multirow{5}{*}{$\begin{array}{l}\text { radiation therapy } \\
\text { (e.g.x x rays, gamma rays) } \\
\text { radioisotope therapy }\end{array}$} \\
\hline ionizing radiation & $\begin{array}{c}\text { CT/CAT } \\
\text { Computed Axial } \\
\text { Tomography } \\
\text { (e.g. xrays) }\end{array}$ & & \\
\hline radioactive isotopes & & $\begin{array}{l}\text { SPECT \& PET } \\
\text { Single Photon Emission } \\
\text { Computed Tomography } \\
\text { and Positron Emission } \\
\text { Tomography }\end{array}$ & \\
\hline \multirow[t]{2}{*}{ magnetic fields } & $\begin{array}{c}\text { MRI } \\
\text { Magnetic Resonance } \\
\text { Imaging }\end{array}$ & $\begin{array}{c}\text { fMRI } \\
\text { functional Magnetic } \\
\text { Resonancel_maging }\end{array}$ & \\
\hline & \multicolumn{2}{|c|}{$\begin{array}{l}\text { DTI Diffusion Tensor Imaging } \\
\text { DSI Diffusion Spectral I maging }\end{array}$} & \\
\hline
\end{tabular}

Although I will not attempt to explain how these different techniques and technologies work, there are still a number of reasons why we should be more explicit about which of these techniques and technologies we have in mind when we ask the relevance question. Firstly, with some of these techniques and technologies we observe the brain while with others we modify it, and this might entail that while some lend themselves more to assessing people's responsibility, others are more relevant to making people more responsible. Secondly, qualitatively different kinds of information are provided by different diagnostic techniques: some provide structural data about brain anatomy, while others provide functional information about which parts of the brain are used in different cognitive tasks; only some provide information about the connections between different brain areas; while some offer high temporal resolution, they usually can not penetrate sufficiently deep into the brain to reveal activity in subcortical regions; and finally, only some of these techniques can reveal the chemical underpinnings of human cognition. Thirdly, the reliability of the information provided by different diagnostic techniques, and the success rate of different 
intervention techniques, varies from technique to technique. Fourthly, some of these techniques are relatively safe, while others either carry significant dangers or else their safety is still unknown. And fifthly, some techniques are much more expensive than others. These differences can bear on whether a given technique or technology is going to be relevant or not, on how relevant it might be, and on the way in which it might be relevant, and so we mustn't allow the single label "neuroscience" to blind us to the fact that we are dealing with many different things and not just a single generic thing called "neuroscience".

Regarding responsibility, this too is not a singular thing. Even at the most coarse level of analysis there are at least two kinds of responsibility concepts-i.e. backward- and forward-looking ones-and as I shall argue in "Which Responsibility?" below, the situation is even more complex because at least six different concepts legitimately answer to the name "responsibility". This means that what we have is not an inquiry into the relationship between one thing (neuroscience) and another thing (criminal responsibility), but an inquiry into the relationship between a diverse range of things on one side (all of the different neuroscientific techniques and technologies) and six things on the other side (the six kinds of criminal responsibility). Thus, the second problem with the relevance question is that before answering it we must first ask "Which neuroscience?" and "Which responsibility?"

But thirdly, this way of putting the question is also problematic because relevance or irrelevance is not really the issue. After all, neuroscience might be relevant to the law either because it challenges its fundamental assumptions, or by seeking to provide an empirical justification for them - in both cases neuroscience would be relevant - but while the former kind of relevance might indeed support a pro law reform stance, the latter would not. On the other hand, the irrelevance of neuroscience to the law might inhere in, for instance, the fact that these two areas lack a common language and a common set of concepts. But although some take this to entail that there is little that neuroscience can contribute to the law, others take this as evidence that the law's picture of how human agents function requires an overhaul. My point is that the same situation can either be described as an instance of neuroscience's relevance- or of its irrelevance, and that neither its relevance nor its irrelevance seems to uniquely entail either a pro or an anti law reform stance, and for these reasons I find this talk of relevance to be unhelpful. Thus, in "Relevance" below I will take a different tact: first, I will highlight several specific questions about responsibility (each related to one of the six responsibility concepts that I will shortly distinguish), and then I will gesture at how various neuroscientific techniques and technologies might help the criminal law to answer those specific responsibility questions.

However, there are limits to how far neuroscience can take us and so, before concluding, in "Limitations" I will list some of these limits.

\section{Which Responsibility?}

In philosophical discussions, responsibility is often talked about as if it were a single, unitary and generic concept. However, at least within the criminal law, the word "responsibility" refers to at least six distinguishable ideas. ${ }^{2}$ To see this, consider a modified version of H.L.A.

\footnotetext{
2 The next two paragraphs (though not the associated footnotes) are taken nearly verbatim from (Vincent 2009c:44-45). Nicola Lacey also claims that "multiple and philosophically variegated conceptions of responsibility are operating within criminal law" (2007:235), though she only distinguishes three conceptions - those based on capacity, character and outcome.
} 
Hart's famous parable about Smith the ship captain (adapted from Kutz 2004:549; adapted from Hart 1968:211):

(1) Smith had always been an exceedingly responsible person, (2) and as captain of the ship he was responsible for the safety of his passengers and crew. However, on his last voyage he drank himself into a stupor, (3) and he was responsible for the loss of his ship and many lives. (4) Smith's defense attorney argued that the alcohol and Smith's transient depression were responsible for his misconduct, (5) but the prosecution's medical experts confirmed that Smith was fully responsible when he started drinking since he was not suffering from depression at that time. (6) Alas, his employer will probably have to take responsibility for this tragedy, since the victims' families' claims for damages far outstrip the limits of Smith's personal indemnity insurance policy.

The word "responsibility" is used in this parable in at least six different ways, each of which suggests a subtly different responsibility concept, and I will now introduce some terminology (derived from Hart's terminology) to give each of these concepts a name so that the upcoming discussion can proceed without the ambiguity inherent in using the generic term "responsibility". ${ }^{3}$ First, there is a claim about his virtue responsibilitySmith was normally a dependable person, someone who took his duties seriously, and who normally did the right thing. ${ }^{4}$ Second, there is a claim about Smith's role responsibilityas the ship's captain Smith had certain duties to various parties, both on and off his ship. ${ }^{5}$ Third, there is a claim about his outcome responsibility - it is alleged that various states of affairs or outcomes, such as the loss of the ship and many of its passengers and crew, are rightly attributable to him as something that he did. ${ }^{6}$ Fourth, there are two claims about

\footnotetext{
3 Although I use H. L. A. Hart's terminology to preserve continuity with his work, there are often important differences between my and his terminology.

4 See (Williams 2008; or Vincent 2009b) for a characterization of this sense of responsibility. Gary Watson's aretaic sense of responsibility is very similar (2004). Also compare (e.g. Haydon 1978; Williams 1995; Bovens 1998; Duff 1998:291).

5 I do not wish to imply that we only have duties in virtue of our roles, nor that it is straight forward to settle who has which duties. As Williams (2008) points out, duties can arise from a plurality of sources and not just from our institutional or social roles. Furthermore, it is also conceivable that a single individual may be subject to a range of conflicting demands at the same time-e.g. some related to their various roles, and others to (e.g.) "the imperatives of basic human decency" (Williams 2008:467) —and that a conscientious person must find the right way to balance them (Williams 2008:459). Furthermore, unlike Robert Goodin (1986; or 1987) who distinguishes what he calls "task responsibilities" from other duties, I use "role responsibility" and "duties" interchangeably to refer to the various things which we ought to do.

6 I use Stephen Perry's term “outcome responsibility" (2000:555) since it captures the idea of a form of responsibility which looks backwards in time to states of affairs (outcomes or actions) that occurred in the past, and for which the person in question is blameworthy, but others have given this concept different names. For instance, Hart calls it "causal responsibility" (1968:212), though I find this name unhelpful since it runs together two distinct ideas-i.e. the normative concept of responsibility (e.g. see Kutz 2004:555; citing Wallace 2002) and what I take to be its causal component. Fischer and Ravizza call it "moral responsibility" (1998), though I am not fond of this name either since although it captures the inherently normative nature of responsibility, it fails to adequately differentiate between our forward-looking moral responsibilities (our "role responsibilities" comprise some of these, though as I argue elsewhere (Vincent 2006:90) we also have other forward-looking responsibilities which I will shortly call "liability responsibility") and the backward-looking moral responsibility which I am presently calling "outcome responsibility". Also, Peter Cane calls this concept "historical responsibility" (2004:162); Thomas Scanlon calls it "responsibility as attributability" (1998:248); Gary Watson calls it the "attributability" sense of responsibility (2004:263-265); and Garrath Williams and Antony Duff call it "retrospective responsibility" (Williams 2008:457, 459, 460 \& 467; Duff 1998).
} 
causal responsibility - Smith's defense lawyer alleged that Smith's aberrant behaviour was caused by the alcohol and by his depression. ${ }^{7}$ Fifth, there is a claim about Smith's capacity responsibility - since Smith was not suffering from depression at that time, the prosecution therefore argued that his mental capacities were fully intact, and hence that his moral agency was unimpaired. ${ }^{8}$ And finally, the parable ends with comments about liability responsibility - about who should now do what to take due responsibility (or maybe even to be held responsible) for what has happened; in this case, the sanction of financial liability is mentioned because that is apparently one way in which responsibility might be taken, but we might also suppose that to personally take due responsibility Smith should also do other things such as apologising to the bereaved families or spending a term in prison.

I take the fact that the word "responsibility" is used here in so many different ways to show that criminal responsibility is more of a syndrome of concepts than it is a single, unitary or generic concept. Furthermore, it also seems to me that claims about these six concepts stand in certain justificatory relations with respect to one another ${ }^{9}$-relations which can be expressed using a structure diagram of the sort that is sometimes used to chart relationships which obtain between premises and the conclusions which they support in philosophical arguments:

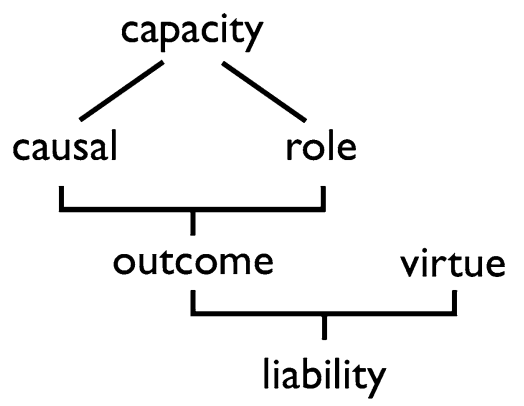

Three groups of justificatory relations are expressed in this diagram. First, this diagram expresses the idea that determinations of outcome responsibility are based in part on claims about the accused person's causal responsibility, but also partly on claims about their role responsibilities. This mirrors the fact that to establish guilt in criminal law we hold an inquiry into two elements: the actus reus (this is where we determine how the accused person acted, and if the crime involved an outcome, whether their action was connected in the right way to that outcome) and mens rea (this is where we determine whether they are culpable). An inquiry into the second element is needed because in criminal law "[a]n adjudication of guilt is more than a factual determination that the defendant pulled a trigger, took a bicycle, or sold heroin. It is a moral judgment that the individual is

\footnotetext{
7 A person's actions may also be cited as a causal factors behind some outcome, though as I shall shortly explain this is not the same as claiming that this person is outcome responsible; rather, I take causal responsibility to be a condition of outcome responsibility.

${ }^{8}$ This example cites a mental kind of capacity responsibility, though I think that other things-e.g. a person's physical strength or tools_could also affect people's capacity responsibility.

9 Lacey also notes "linkages between particular conceptions of responsibility" (2007:234), however the links which she notes are different to the ones that I will list.
} 
blameworthy" (United States v. Lyons 1984). ${ }^{10}$ But since a person can be blameworthy either on account of having acted with a culpable mental state (e.g. because either intentionally, knowingly or recklessly they acted contrary to how they should have acted) or due to negligence (i.e. because although not knowingly, objectively they still acted contrary to how they should have acted), to establish whether a person is to blame for how they acted we must therefore first determine how they should have acted —or put in my terms, we must first establish what were their role responsibilities. ${ }^{11}$ Put another way, to turn a finding of causal responsibility (i.e. that the accused person acted in a prohibited way, or that through their actions they brought about a prohibited state of affairs) into the fully-fledged moral accusation of outcome responsibility (i.e. that they are guilty of a crime), the criminal law also requires that the accused party must have violated their role responsibilities (i.e. that they either knowingly did the prohibited thing, or that although not knowingly they still never the less failed to do what they ought to have done given for instance such things as the circumstances of the case and their abilities).

Second, this diagram also expresses the idea that claims about a person's capacity responsibility can bear on what may legitimately be said about their causal responsibility and about their (and others') role responsibilities. Regarding the relationship between capacity responsibility and causal responsibility, the body movements of (e.g.) a person suffering from an epileptic fit will rarely be seen as instances of genuine action-in the absence of voluntariness (see the next paragraph), such body movements tend to be conceptualized as something that happened to that person rather than as something that they did-and this in turn undermines the claim that their actions caused some untoward state of affairs, precisely because on this account those were not instances of their actions. Arguably, the "automatism" defence also works by denying that (e.g.) the sleep walker's body movements count as actions; although those body movements may have played an important causal role in generating some state of affairs, those body movements are not something which can be attributed to that person qua actions.

Regarding the relationship between capacity responsibility and role responsibility, it might however be argued that a person with epilepsy has a role responsibility to take antiepileptic medication (or if their epilepsy can't be controlled through medication or other means that they should refrain from activities that might unduly endanger others such as driving) and that someone who fails to do this may still be culpable on account of that (Sapolsky 2004:1788, 91 \& 93). But in law, a person's reduced capacity responsibility will often have the opposite effect on their role responsibilities-i.e. rather than expanding them as in the epilepsy example, the scope or range of a person's responsibilities might contract or shrink. This is, for instance, how we think about children and others whose mental capacity falls below the minimum threshold of fully responsible moral agency; their reduced capacity is taken as a reason to excuse them or to expect less of them, and thus

\footnotetext{
${ }^{10}$ For instance, even if Jones' bullet struck Smith's heart, we would hesitate to say that Jones was responsible for Smith's death if we learnt that Smith had unexpectedly ran onto a designated, clearly marked and fenced off shooting range and into the path of Jones' bullet, or that Jones was compelled to shoot Smith by Brown who pointed a loaded gun at Jones' head and threatened to pull the trigger unless Jones shot Smith. This also mirrors Joel Feinberg's suggestion that "blame-fixing" requires both a genuine causal relationship between the thing that does the causing and the thing that is allegedly caused, as well as a moral element (1970:207). Watson also argues that we would not hold someone to be responsible for something bad unless we take what they did "to be contrary to one of [their] responsibilities" (2004:274).

11 That culpability in criminal law sometimes hinges on an assessment of the accused person's subjective mental states, while at other times it hinges on more objective judgments about whether they violated reasonable norms, is also noted by Westen (2008) and by Lacey (2007:237). I comment further on this in "What Were P's Role Responsibilities, and Were They Breached?" below.
} 
subsequently to morally blame them for less. However, the relationship between capacity and role responsibility is even more complex than that, because not all instances of reduced capacity - for instance, not ones for which the person is responsible (e.g. drunkenness)reduce the range or scope of a person's role responsibilities. ${ }^{12}$ And lastly, facts about one person's capacity responsibility may even bear on another person's role responsibilities. For instance, parents who learn that their child is more prone to impulsive behaviour than other children might under some circumstances acquire a special role responsibility to check up more on what their child is getting up to, and thus they might be more prone to accusations of negligence when their child gets up to mischief while they weren't watching. In broad terms, the criminal law expects people with greater capacities to conform to higher standards of behaviour-i.e. the criminal law is capacitarian in the sense that it is generally held that responsibility tracks capacity - and the law's attitude in this regard can either be explained in a positive way by saying that the more a person is capable of doing (i.e. the greater their capacities) the more it is reasonable to expect of them, ${ }^{13}$ or in a negative way by saying that people whose capacities non-culpably fall below a certain threshold have legitimate excuses for acting as they did. ${ }^{14}$

Third, this diagram also expresses the idea that conclusions about how a person should take liability responsibility - or, taken from society's perspective, about the kind of liability responsibility that should be imposed onto them-or about the extent of the liability responsibility that they should take, are affected by prior findings about that person's outcome responsibility and by the degree of their virtue responsibility. After all, punishment (one form of liability responsibility) is normally only imposed onto those whom we previously found to be outcome responsible for a punishable offence, and the kind and degree of their punishment depends in part on the seriousness of the sort of thing for which they are outcome responsible (i.e. homicide, arson, theft, etc.) and on the degree of their role responsibility for it. But another consideration that is also taken into account at the sentencing stage (often to reduce the severity of the punishment, but it can also justify increasing its severity) is the person's character-e.g. whether this is their first infraction with the law and previously they had a "clean slate", or whether they are hardened criminals or repeat offenders who should have learned from past experiences rather than re-offending. In other words, at the sentencing stage a person's virtue responsibility can be a mitigating factor and its lack can be an aggravating factor, by modulating the kind and degree of punishment that is imposed upon them (see Lacey 2007:240, 245-247). ${ }^{15}$

In law, responsibility is not a single concept, but it is rather a syndrome of at least six concepts which are related to one another by a common word and by a number of justificatory relationships that are often expressed in legal discourse and practice, as depicted above in the structured taxonomy of responsibility concepts. Thus, the question "How is neuroscience relevant to criminal responsibility?" is actually shorthand for at least six separate questions, each pertaining to a different responsibility concept.

But before moving on, I should say a few words about why I think that we need all of these concepts. After all, the claim that there is more than one generic responsibility concept is not new-it is explicitly noted by an increasing number of philosophers (e.g.

\footnotetext{
12 See point five of "Limitations" below.

13 On the positive account, capacities are one of the grounds of our role responsibilities.

14 On the negative account, regardless of what grounds our role responsibilities, non-culpable reductions in capacity may provide legitimate excuses to departures from them.

15 The so-called "three strikes laws" demonstrate how a judgment that someone lacks virtue responsibility can be an aggravating factor at sentencing.
} 
Scanlon 1998; Duff 1998; Cane 2002:31) —and the usual two-pronged distinction suffices to recognize such things as that while the criminal law's guilt determination stage concerns itself with determinations of backward-looking responsibility, the sentencing stage concerns itself with impositions of forward-looking responsibility. So what is the purpose of multiplying responsibility concepts to the degree which I recommend? What is gained?

In reply, apart from the need to capture the different senses of the term "responsibility" that were exemplified in the parable about Smith, the more common way of carving up the domain of responsibility concepts into these two sub-domains is inadequate for at least two reasons. First, it is inadequate because concepts like capacity responsibility and virtue responsibility look neither backward nor forward in time, but rather they describe a kind of agent (one at the level of capacities, the other at the level of character). ${ }^{16}$ Second, it is not true that the guilt determination stage concerns itself only with backward-looking responsibility. After all, an important part of the guilt determination stage involves an inquiry into role responsibility-we do this, as I suggested, to figure out if the accused person should be blamed for how they acted, which is in turn needed to convert causal responsibility into the fully-fledged moral accusation of outcome responsibility-and this (i.e. role responsibility) is a distinctly forward- rather than a backward-looking responsibility concept.

To accommodate the richness of legal discourse, we need a sufficiently rich taxonomy of responsibility concepts-one which recognizes rather than obliterates the different meanings behind the single word "responsibility", and one which recognizes that claims about one kind of responsibility bear on claims about other kinds of responsibility — and that is what the above structured taxonomy of responsibility concepts is meant to provide.

\section{Relevance}

If the question that was being asked was "Is neuroscience relevant to criminal responsibility?", then my suggestion would now be that before this question can be answered we should first ask "Which responsibility?" and "Which neuroscience?". However, I think that a better way to proceed is to recognize that for each of the six responsibility concepts the criminal law asks a different question (in what follows, $P$ stands for "person" and $O$ is their action or an outcome of that action):

\section{[1] Is $P$ (outcome) responsible for $O$ ?}

[2] Were $P$ 's actions (causally) responsible for $O$ ?

[3] What were $P$ 's (role) responsibilities, and were they breached?

[4] Is $P$ a fully (capacity) responsible person?

[5] Is $P$ a (virtue) responsible or an (virtue) irresponsible person?

[6] How should $P$ take (liability) responsibility for what they did?

The first question asks whether the accused was guilty of the crime-i.e. the guilt determination stage culminates in an answer to this question. However, the next two questions inquire into the two components that inform the criminal law's answer to the first question: the second question inquires about how the accused person acted and what effects those actions had (i.e. actus reus), and the answer to the third question informs us

\footnotetext{
${ }^{16}$ For the present moment I put aside the question of how to navigate the distinction between capacity and virtue responsibility, but I return to this question in "Is $P$ a Virtue Responsible or a Virtue Irresponsible Person?" and "Limitations". below.
} 
about whether they were culpable in having acted like that (i.e. mens rea). The fourth question asks about the accused person's moral agency-i.e. whether they are fully responsible moral agents or whether their agency is somehow diminished. The fifth question is an inquiry about the accused person's character and about their history-i.e. it tries to ascertain what sort of person they are (e.g. good or bad). And the sixth question asks how this person should now be treated-e.g. whether they should be punished, if so then in what way and how severely; the sentencing stage culminates in an answer to this sixth question. A different kind of query is raised by each of these questions, and it is conceivable that different neuroscientific techniques and technologies may find different kinds and degrees of application in addressing these queries.

Furthermore, each of these questions is asked with different frequencies at different stages of the criminal process. For instance, questions 1-4 are particularly relevant to the guilt determination stage; questions 1,5 and 6 are most obviously relevant to the sentencing stage; and questions 5 and 4 are also relevant to parole decisions. Thus, different neuroscientific techniques and technologies may be differentially useful at the different stages of the criminal process.

In what follows, I list some ways in which various kinds of neuroscience might help us to answer some of these more precise responsibility questions.

\section{Is $P$ Outcome Responsible for $O$ ?}

This is the main question that the guilt determination stage addresses. Another more nuanced way of putting this question-more nuanced because it recognizes that responsibility comes in degrees-might be "How (outcome) responsible is $P$ for $O$ ". However, the criminal law addresses this question indirectly via two inquiries: one into the actus reus which relates to causal responsibility, and another into mens rea which relates to breaches of role responsibility. Thus, neuroscience's role in helping to address the outcome responsibility question will be via the help that it offers in addressing the causal responsibility and role responsibility questions, which I discuss in the following two sub-sections.

\section{Were P's Actions Causally Responsible for $O$ ?}

Roughly, to answer this question we must uncover such facts as "Where was $P$ at the time of the crime?", "Precisely how did $P$ act?", and "Were $P$ 's actions causally implicated in generating $O$ ?". Given the epistemic hurdles that stand in the way of answering such questions, it is conceivable that neuroscience might be useful here in the following ways.

Firstly, fMRI-based lie detection techniques such as those under commercial development by companies like No Lie MRI (2009) and Cephos Corp (2009) might mature sufficiently to become helpful in the cross-examination process to reveal whether witnesses are intentionally trying to deceive us. Alternatively, rather than trying to detect when someone is intentionally trying to deceive us, we might instead attempt to compel them to tell us what they take to be the truth (about how people acted, and what effects those actions had); for instance, perhaps new truth drugs might be developed, or the recently reported-on (Rosen 2007; Coukell 2006) technique that is currently being investigated by F. Andrew Kozel and Mark George which uses TMS to temporarily subdue parts of the brain that are allegedly involved in intentional deception might become perfected. Thirdly, the success rate of brain finger printing techniques, such as Lawrence Farwell's (Farwell and Smith 2001) Memory and Encoding Related Multifaceted Electroencephalographic Response (MERMER) technique which monitors the witness' brain for the P300 wave and 
other associated indicators, might be used to establish which witnesses are personally acquainted with important pieces of physical evidence, and that in turn might provide further clues about whom or what further cross-examination should focus on. And fourthly, once our knowledge of the brain becomes sufficiently sophisticated to allow us to detect in organic terms the presence of various medical conditions that affect the brain, we might consult neuroscientific evidence to assess the plausibility of an accused person's "automatism" defense-for instance, like Kevin Parks' (Broughton et al. 1994) claim that he killed his mother in law and nearly killed his father in law while sleep walking-by checking for signs in their brain that might verify their claim that they are afflicted by that condition.

In similar ways to how other forensic techniques are currently used to overcome the epistemic barriers that stand in the way of us learning pertinent facts-facts that inform answers to the causal responsibility question - so too lie detection and brain finger printing techniques like those based on fMRI and EEG, truth-compelling drugs and TMS, and our knowledge of how various brain conditions that affect bodily movement physically manifest themselves in afflicted people's brains (or rather, future improved versions of such techniques and technologies) might also help us to overcome some of these epistemic barriers.

\section{What Were P's Role Responsibilities, and Were They Breached?}

Because the criminal law assumes that intentions matter to the wrongness of an actroughly, it is held that culpability decreases in line with whether an act is performed intentionally, knowingly or recklessly_people are taken to have a role responsibility to not intentionally wrong others, to not be indifferent when they knowingly pose an imminent danger to another's interests, and to not knowingly take unreasonable risks with others' interests. We have a role responsibility to not knowingly (i.e. with awareness) do such things, and when we do knowingly do them we breach that role responsibility. ${ }^{17}$ To the extent that culpability varies in criminal law with the precise mode of knowingly committing an actus reus, the already-mentioned lie detection and related techniques could conceivably be used in the following ways to help us determine if the accused person breached their role responsibilities. For instance, lie detection techniques might be used in conjunction with questions like "Did you intend to do that?" or "Were you aware of a risk that that might happen?", to help us gauge whether the accused person believes that they acted intentionally, knowingly or recklessly. Alternatively, Aharoni and colleagues have suggested that we could also check for problems with the accused person's brain that can plausibly undermine their ability to reliably form intentions or to reliably act from such intentions once formed, because if such problems are discovered then this may raise sufficient doubt about whether the accused person indeed acted with the mens rea which is required by that crime (2008:1128-1129).

However, as the existence of negligence suggests, culpability in criminal law is not necessarily tied to the question of whether the accused person acted in one of these culpable knowing kinds of ways - i.e. culpability is not intrinsically tied to people's mental

\footnotetext{
17 T. M. Scanlon's recent claim that an agent's intentions do not change the permissibility of an action but only how we assess that agent, seems to me to capture the criminal law's interest in subjective culpabilityi.e. this interest reflects the plausible intuition that committing an actus reus in a knowing kind of way (e.g. purposefully, knowingly or recklessly) is worse than doing so in a not-knowing kind of way (e.g. negligently or even innocently) (2008).
} 
state. For instance, people are also culpable when they fail to be sufficiently careful-when they fail to observe the role responsibilities that a reasonably prudent person would have observed-and here it is not their mental state that makes them culpable (unless perhaps we speak of their lack of forethought as a mental state (e.g. see Lacey 2007:242)) but rather that they should have acted with greater caution (i.e. that they had a role responsibility to act in a different way). Arguably, the criminal law cares about people's mental states only because doing something bad intentionally, knowingly or recklessly-i.e. in these knowing kinds of ways-are specific ways of breaching our role responsibilities. But to the extent that we have more role responsibilities than just to avoid doing bad things in a knowing kind of way, it is conceivable that neuroscience might also help us to assess people's role responsibilities by providing tools to assess their mental capacities. This might work in two ways. Firstly, we might use neuroimaging techniques to assess an accused person to determine what mental capacities they are likely to have had when they committed an actus reus and thus to determine what role responsibilities it is reasonable to expect them to have observed. ${ }^{18}$ Secondly, we might also use neuroimaging techniques to assess one person's mental capacities ahead of time, in order to determine what role responsibilities another person-e.g. the scanned person's guardian — should observe, which may later help us determine whether the guardian breached their role responsibilities in acting as they did.

Thus, neuroscience might help us to answer the role responsibility question in two ways, depending on whether we want to determine if the accused person was subjectively culpable (i.e. whether they committed an actus reus in one of the prohibited knowing kinds of ways) or objectively culpable (i.e. whether they failed to do something that they ought to have done, or did something that they ought not to have done). Lie detection and related techniques as well as certain determinations of people's capacity may be useful for detecting subjective culpability, and assessments of capacity responsibility might help us to settle what role responsibilities it is reasonable to expect them to have observed.

\section{Is $P$ a Fully Capacity Responsible Person?}

However, before anyone's role responsibilities can be assessed via an assessment of their mental capacities, we first need a theory about precisely which capacities matter-i.e. which mental capacities an individual requires to be a fully capacity responsible person; for instance, whether only rationality is required, or whether various affective responses are also needed-and how neuroscientific techniques and technologies might be used to measure the degree to which someone possesses those capacities.

Thus, the first place where neuroscience might find application in addressing the capacity responsibility question is at the theory-building stage (i.e. back at the lab) where we develop our theories concerning what capacities-and importantly, what related brain areas, mechanisms, circuits or neurochemicals-are used (and perhaps even required) by people whom we normally take to be capacity responsible. Put a different way, neuroscientists might try to discover the neural correlates of capacity responsibility, and this is plausibly what the work that is being done in the field of moral cognition might provide (e.g. Haidt 2001; Greene and Haidt 2002; Moll et al. 2005)-i.e. insight into how the cognitive and volitional capacities that are often taken to be a pre-condition of responsible moral agency are implemented in the brain. Similarly, incidental medical findings like those reported by Burns and Swerdlow (2003) - namely, of a 40 year old school teacher who developed an obsession with child pornography due to a tumour that pressed on his

${ }_{18}$ I explain my presuppositions behind this suggestion in notes 13 and 14 above and in the surrounding text. 
orbitofrontal region, and who was unable to stop himself from acquiring such pornographic material (and doing various other things) despite knowing that what he was doing was wrong-might also provide some valuable clues to how functions performed by different parts of the brain contribute to making a person capacity responsible. ${ }^{19}$ I will not however comment on whether the criminal law should be revised to take account of such studies and findings - for instance, whether we should decide that rationality is not after all the touchstone of responsible moral agency; or perhaps whether we should acknowledge the possibility that at least some (if not all) people whom we currently think of as "bad" might in fact be afflicted with as-yet-undetected medical conditions (just like Burns \& Swerdlow's patient would have been a century ago) and hence that they should be re-classified as "sick" (e.g. see Tancredi 2005:143-161) — since my point is only that it is not so difficult to see how neuroscientific research might engage with debate in the philosophy of law about what constitutes capacity responsibility.

Secondly, still at the theory-building stage, neuroscientists might develop techniques and technologies to measure the extent to which a particular person possesses the capacities which we believe are required for responsible moral agency. As I have argued elsewhere (Vincent 2009a:11-13), it is relatively easy to see how the discovery of a significant structural brain abnormality might provide evidence of reduced mental capacity-namely, if the brain mechanism in which a particular mental capacity is normally housed exhibits physical damage, then it is likely that the related mental capacity will also suffer (putting aside complications presented by brain plasticity). But it is more risky to view functional abnormalities in this same way because the fact that someone's brain exhibits (e.g.) abnormally low patterns of activity in an area that is usually associated with moral judgment, might simply only show that they are not exercising their capacity for moral judgment rather than that they can not exercise that capacity. This need not put a nail in the coffin of functional neuroimaging, however it may limit the context in which it makes sense to use such technology. For instance, it might be a reason to only use functional neuroimaging when we build our theories about which parts of the brain are used to perform which cognitive functions, and only if we can be relatively confident that the subjects with whom we are working have little reason to deceive us about whether they are indeed trying to perform the mental tasks that we ask them to perform. However, it may not be reasonable to use functional neuroimaging to test whether a specific person that stands accused of responsibility for something - some accusation which carries with it a hefty legal penalty-possesses some capacity that is allegedly required for responsible moral agency, because it is possible that the reason why the part of their brain that is normally associated with that capacity will not show up on the functional scan of their brain is because they were not really trying to exercise that capacity. My point is that different techniques and technologies may need to be developed for testing specific individuals for the possession of a particular capacity, than the techniques which were originally used to discover which capacities (and related brain mechanisms) are required for responsible moral agency.

Finally, once we are satisfied that we understand the neurological correlates of capacity responsibility, and that our tools and techniques can accurately measure the degree to

\footnotetext{
${ }^{19}$ Burns \& Swerdlow suggest that this case supports the hypothesis that the orbitofrontal cortex plays a role in impulse control. After all, their patient retained moral knowledge-presumably this knowledge was contained in another part of their brain-but that knowledge was causally inefficatious since their compromised orbitofrontal cortex wasn't able to utilize it to tone down the impact of their sexual impulses on their manifest behaviour (2003:438-440).
} 
which a particular person possesses various capacities, we will then be ready to enter the court room and begin the theory-application stage. Here, the neuroscientific techniques and technologies that were developed at the theory-building stage (previous paragraph) may be utilized to assess the capacities of the accused. But it is also plausible that we might use them to assess the capacities of judges, juries and witnesses, to see whether they are competent ${ }^{20}$ to perform their functions or role responsibilities, or maybe to detect biases and prejudices that might otherwise cast doubt on the objectivity or reasonableness of their decisions.

Alternatively, intervention techniques might also help us to make people more capacity responsible (rather than just checking who is and who is not capacity responsible). For instance, that is what Burns \& Swerdlow did when they removed the tumour that was pressing on their patient's orbitofrontal cortex and which temporarily (for the duration that the tumour was there) turned him into a paedophile and a sex addict-i.e. they restored his capacity for self-control. ${ }^{21}$ Also, to the extent that various diseases like obsessive compulsive disorder can reduce a person's ability to control their actions, treatments for those diseases-like anti-depressant drugs, or more recently like Damiaan Denys' use of deep brain stimulation (Jancin 2008) - may also qualify as ways of repairing their capacity responsibility. Finally, the administration of cyproterone acetate - an anti-androgen that is sometimes used in the treatment of repeat sex offenders as a form of "chemical castration" to reduce their sex drive-is another way to help some people regain control over their actions.

In summary, neuroscience might help to address the capacity responsibility question at two stages. Firstly, at the theory-building stage neuroscientists might set out to discover the neurological correlates of capacity responsibility, and to develop techniques and technologies that can measure the degree to which an individual possesses those capacities. Second, once we are satisfied with the correctness of our theories and with the accuracy of our measuring instruments and techniques, we will then be able to proceed to the theoryapplication stage either by helping courts assess people's capacities or by using intervention techniques to restore people's capacities. ${ }^{22}$ I take it that most disagreement and debate will concern the first stage.

\section{Is $P$ a Virtue Responsible or a Virtue Irresponsible Person?}

I am not sure whether neuroscience can help us to answer the virtue responsibility question-i.e. to determine whether someone is a responsible or an irresponsible person (both in the virtue sense of the term), and to discover the particular ways in which they might be prone to irresponsibility (e.g. maybe they are easily angered and prone to fly off the handle). What makes this question difficult is a conceptual issue-namely, I am not sure how we are to distinguish between the neural correlates of virtue responsibility and the neural correlates of capacity responsibility. Put a different way, suppose we find that the features of a particular area of the brain are invariably correlated with whether a person is easily angered and prone to fly off the handle or not, and then we discover that the brain of

\footnotetext{
${ }^{20}$ Meynen (2009) discusses similarities between medical competence and capacity responsibility.

21 I describe this as a volitional capacity restoration, rather than a cognitive capacity restoration, because judging by his self-reports the patient evidently knew that what he was doing was wrong, however he couldn't resist doing it despite this knowledge.

22 Thanks to Greg O'Hair from Flinders University for pointing out that the different uses of neuroscience relate to differences in the theory-building and theory-application stages.
} 
a particular individual called Angry Jones exhibits precisely those features and that he is indeed also easily angered and prone to fly off the handle. Precisely what would such findings about Angry Jones tell us? Would they entail that Angry Jones has reduced capacity to control himself and thus that this provides some basis for exculpating him when he does fly off the handle, or would they simply echo what we already knew-namely, that he is an unsavoury character (i.e. not virtue responsible). One problem here is that we don't really need neuroscience to tell us that Angry Jones is angry, since we already have ample behavioural evidence of his hot temper, and this has prompted the complaint that neuroscience doesn't really seem to add anything new which we didn't already know (e.g. see Morse 2004, 2006:48). Another problem though, and the one which worries me here, is that it is not immediately clear whether what we would have discovered by obtaining the scans of Angry Jones' brain is proof of his reduced virtue responsibility (i.e. that Angry Jones is an irresponsible man with a hot temper), or proof of his reduced capacity responsibility (i.e. that Angry Jones is not a fully responsible person) (e.g. Reimer 2008; Maibom 2008).

I think that this conceptual issue presents one of the biggest challenges to using neuroscience in the courtroom-i.e. to helping the law to answer its various responsibility questions-because it points to an uncomfortable tension between two apparently incompatible ways of looking at the same data. This problem may be overcome if we find a principled way to draw a conceptual distinction between a person's character and their capacities, or an empirically valid way of distinguishing the neurological correlates of character from the neurological correlates of capacities, however I am not aware of how this might be done. I return to this worry in point three of "Limitations" below.

\section{How Should $P$ Take Liability Responsibility for What They Did?}

I said earlier that how a person will be treated (i.e. what liability responsibility will be imposed onto them) depends in part on what they have done (i.e. on what they are outcome responsible for and on the degree of their outcome responsibility for it) and partly also on what they are like as people (i.e. on their virtue responsibility). Thus, whatever light neuroscience can shed on the outcome responsibility and virtue responsibility questions will also help to illuminate the liability responsibility question.

However, how a person shall be treated also depends in part on what we take to be the criminal law's aims-i.e. what the criminal law is trying to achieve. Some plausible answers include: (1) retribution, (2) general and specific deterrence, (3) reform and education of the offender, (4) quarantine of dangerous people to protect society, and (5) expression of society's solidarity with victims by publicly condemning offenders' actions. I think that neuroscience might help to answer the liability responsibility question by helping the criminal law to better achieve at least the first three of these aims.

Firstly, if retribution is the law's aim in holding people responsible, then perhaps neuroscience can help us to figure out whether a particular person is even a valid candidate for retribution. Retribution is a valid response to only some kinds of agents-namely, only those who can understand that what they have done is sanctioned, and that the way in which they will now be treated is the law's response to what they have done (i.e. an instance of such a sanction). Thus, should diagnostic data suggest that a particular person lacks the capacity to comprehend that they are being punished (rather than just that they are being maltreated), then that may be a reason to not punish them for the sake of retribution (although we may still have reason to, for instance, imprison them so as to protect society, etc.). Alternatively, drawing inspiration from the execution of Charles Laverne Singleton on January 6, 2004 in Arkansas, USA (2004), medical treatments might be developed that 
raise people's mental capacities back up to a sufficiently high level so that they may again be capable of understanding that they are about to be punished-i.e. to help them again become legitimate candidates for retributive punishment (Latzer 2003). ${ }^{23}$ Finally, as Adam Kolber has suggested, we might use neuroscientific techniques and technologies to calibrate the precise kind and degree of punishment that will be inflicted on specific parties, so as to take account of their "subjective experience of punishment" (2009). After all, if we accept retribution as a legitimate aim of the criminal law and we believe that similar crimes should receive similar punishments, then since the way in which different people experience the same physical treatment may differ from person to person-for instance, I might have a much higher tolerance for pain than you do-the punishments that we inflict may need to be customized to the person onto whom they will be inflicted. One way to do this is to develop techniques and technologies that make it possible to get an insight into how different people experience various punishments, and that on Kolber's account is something that neuroscience may shortly provide (e.g. see Kolber 2009:422-423, 2007).

Secondly, if deterrence is the law's aim in holding people responsible-either specific deterrence to prevent an offender from re-offending, or general deterrence that sends out a message to others so that they do not do what the offender did (Calabresi 1970) - then neuroscience might help by identifying particular sensitivities that humans have to specific punishments. For instance, Oliver Goodenough and Kristin Prehn tender the suggestion that a possible explanation for why intellectual property rights are infringed more often than tangible property rights is because at a basic cognitive level we perceive intellectual property in a very different way to how we perceive tangible property, and that this perceptual difference means that at an emotional level humans lack the capacity to take seriously the idea that (e.g.) a copyright violation "is a serious injustice" (2004:99). Their hypothesis is that at an emotional level intellectual property just doesn't seem like real property to us, and hence they float the suggestion that perhaps the interests of those who produce what we now call "intellectual property" may be better secured through something other than a kind of property law, since this kind of law evidently isn't very effective at deterring people from committing (e.g.) copyright violations. It is difficult to tell what will and what won't work well as a deterrent ahead of time because this is an empirical and not a conceptual matter, but we can certainly improve our chances of effectively deterring people through the punishment that we inflict by enriching our understanding of how the organ that enables the human mind works-i.e. by building up more sophisticated scientific behavioural models (e.g. see Jones 2004; or Goodenough and Prehn 2004:90) —and that is again something to which neuroscience can contribute.

Finally, if the aim of holding people responsible - of treating them in various ways to get them to take liability responsibility for what they have done-is to reform or educate them, then neuroscience may also help by assessing the effectiveness of various kinds of punishments (qua attempts at reform), or by providing alternative ways of reforming people rather than just, for instance, locking them up. If we want offenders to improve morally-i.e. to address their deficits in capacity and virtue responsibility-then perhaps neuroscience can come up with medical treatments that help to make irresponsible and non-responsible people more responsible (in both the virtue and capacity senses). For instance, Thomas Douglas has suggested that to the extent that "aversion to certain racial groups, and impulses towards violent aggression" implicate the amygdala and "a

${ }^{23}$ We need not endorse capital punishment to endorse this suggestion; for instance, our aim might be to ensure that the retributive aspect of imprisonment is comprehended by prisoners. 
polymorphism in the Monoamine Oxidase A gene" (2008:233), we might be able to selectively target those causes (if that is what they are) with various intervention techniques such as (e.g.) TMS or psychotropic drugs. Such a high-tech approach to "moral enhancement" —or perhaps to moral treatment—might be a lot more effective and much cheaper than standard techniques (e.g. locking someone up in prison), and so this is another way in which neuroscience might help the criminal law to address one of its responsibility questions - i.e. by providing alternative ways of reforming people.

\section{Summary}

The criminal law asks many different kinds of responsibility questions:

[1] Is $P$ (outcome) responsible for $O$ ?

[2] Were $P$ 's actions (causally) responsible for $O$ ?

[3] What were $P$ 's (role) responsibilities, and were they breached?

[4] Is $P$ a fully (capacity) responsible person?

[5] Is $P$ a (virtue) responsible or an (virtue) irresponsible person?

[6] How should $P$ take (liability) responsibility for what they did?

These questions present tractable problems which neuroscientists can at least try to address, and in this section I have suggested some ways in which I think that these problems can be addressed by neuroscience. But to see how neuroscience might be relevant to criminal responsibility, we had to clearly distinguish the diverse range of responsibility questions that the criminal law asks, and that in turn required us to notice that in criminal law responsibility is more of a syndrome of related concepts rather than a single, unitary and generic concept.

\section{Limitations}

The previous section's discussion highlighted a number of ways in which neuroscientific techniques and technologies might help us to answer the criminal law's diverse responsibility questions. But the image that I painted was too rosy, and I do not wish to leave the reader with an unrealistic impression of what neuroscience can do for us. Hence, I will now list six groups of reasons why neuroscience can only be so useful, but not more, in addressing these questions.

The first limitation relates to science and technology. Our current understanding of how the brain enables the mind is dreadfully basic. Our current technology is also at very early stages of development, and the data that it provides is very coarse-grained and sketchy at best, and it is not clear whether this data is even ecologically valid-i.e. whether the findings of controlled lab-based studies can really inform our decisions in courtrooms about complex real-life cases. Although we can be optimistic and hopeful that a bright future awaits when science and technology have advanced sufficiently far to enable us to do the sorts of things which I have mentioned, right now is not that time and so we should exercise caution when relying upon current neuroscience to answer the criminal law's diverse responsibility questions.

Secondly, there are various applied ethics issues which need to be considered. For instance, we should think carefully before we compel people to undergo brain scans (e.g. to see what they know) or to force them to take medications (e.g. to make them more responsible in the capacity or virtue senses) since doing so involves a substantial 
impingement on their person, it may impose upon them substantial risks of harm and maybe even harms, and in the end we may consider such procedures to be too invasive and un-dignifying to ever be inflicted upon anyone. My aim in citing examples of how technology might be used was not to endorse any of those uses or to suggest that the applied ethics issues have already been resolved, but only to point out what's possible. But whether what's possible is also justified is a separate question that I have said nothing about.

Thirdly, I have already mentioned my worries about how to distinguish evidence for diminished capacity responsibility (which on my account can exculpate under the right circumstances) from evidence for a lack of virtue responsibility (which if anything plays quite the opposite role because we tend to treat the irresponsible more harshly than how we treat the non-responsible). But until we find a satisfactory way to demarcate the bad from the mad, this conceptual difficulty will pose a significant stumbling block. To be fair, this is a general problem faced by all capacitarian theories of responsibility including those of John Fischer and Mark Ravizza (1998) as well as Glannon (2002), and as I optimistically suggested earlier, perhaps this problem might find a satisfactory conceptual or empirical solution - for instance, maybe we will find a convincing basis for distinguishing character flaws from character disorders. I am doubtful that the solution will be this simple, but in any case this is not a problem that capacitarians should ignore for too long, because delays may prompt our society to revert to an earlier nineteenth century model in which guilt determinations rely on assessments of reputation and character rather than capacity - a model which perpetuated class inequalities by allowing prejudices against lower socio-economic classes to influence guilt determination decisions (Lacey 2007: 246-249).

Fourthly, normative assumptions play a crucial role in how we answer many of the listed responsibility questions. For instance, although neuroscience might tell us that the human brain is not completely mature until around the age of 21 (Gogtay et al. 2004; APA 2004:21-23; Blakemore and Choudhury 2006) and maybe even 23 (Snead 2008:32) and hence that our capacities are not yet fully developed until we reach that age, neuroscience can't tell us just how mature a person must be-or more precisely, just how much of a relevant capacity they must possess-in order to pass the threshold at which they can be considered a fully responsible person; that is something for us to decide. Also, only we can decide just how much care a person must take in the conduct of their activities in order to avoid being seen as negligent if things go wrong; how much care is enough is again not a neuroscientific but a normative issue. Similarly, it is also up to us to decide what is the right kind and degree of retributive punishment for a given crime (though note the discussion in "How Should $P$ Take Liability Responsibility for What They Did?" above on calibrating retributive punishment)—for instance, whether the appropriate kind and degree of punishment for theft is a fine, incarceration, ten lashes of the whip, twenty lashes, amputation of the hand that stole the item, or execution of the offender. Finally, the fact that someone actually lacks a given capacity will not exculpate them if we also think that they ought to have developed that capacity. For instance, I would not be excused for failing to give a lecture which I promised to give on the excuse that I lacked the knowledge (and thus the capacity) to give that lecture, if the reason why I lacked that knowledge was simply because I didn't get around to preparing myself. The point is that I should have acquired that capacity and the fact that I didn't actually acquire it is not something that can exculpate me. This echoes Morse's earlier comment that the fact finding mission can only take us so far, since responsibility determination is also in many important ways a norm setting exercise. 
Fifthly, history also imposes limits on just how useful neuroscience can be in helping us to answer the criminal law's various responsibility questions. For instance, we can't go back in time to check the accused person's capacities at the precise moment when they committed the crime, and so we must rely on the assumption that their brain and related capacities have remained largely unaltered. But given how long criminal cases can take to come to trial and hence for the accused person's brain to be examined, this assumption may be questionable at best (or perhaps this is a reason to scan all suspects as soon as they are apprehended). Furthermore, at least prima facie it seems to matter how a person came to have the particular (in)capacities that they actually have, but this history is not necessarily revealed in static images of the brain since all that we see when we examine a person's brain is the end result of that history. For instance, the fact that someone is responsible for their current incapacity ${ }^{24}$ is often taken as a reason to discount the exculpatory value of that incapacity - that is after all why it's no excuse for the driver involved in a hit-and-run car accident to say "But your honour, I was drunk at the time and so I couldn't possibly have driven any better than I actually did, and so why do you expect me to do what I actually couldn't have done?". Finally, it also matters whether the person knew about their incapacity because if they did then maybe they should not have placed themselves in a situation where that incapacity may lead to problems; or maybe they should have done something to avoid it manifesting (e.g. like the epileptic who takes their medication). History matters in important ways - as Fischer and Ravizza note, "the history of ... an action is crucial to the issue of whether the mechanism that leads to it is the agent's own" (1998:197) — but pictures of the brain may be largely mute about this history, since all that they show is the end result.

Sixthly, and finally, procedural legal issues may stand in the way of using neuroscientific techniques and technologies to help the law answer its diverse range of responsibility questions. For instance, the technology may not be sufficiently reliable for the law to base its decisions upon it, especially given that so much can hang on these decisions. ${ }^{25}$ Furthermore, rather than providing genuinely useful information from which to deliberate upon about the given case, colourful pictures of lit-up brain regions and scientific graphs may instead only confuse and mislead judges and jurors (Weisberg et al. 2008), and this may undermine their probative value. Alternatively, maybe extracting information about the crime directly from people's brains violates their procedural right to remain silent and to not incriminate themselves (Tovino 2007:50-51). On a different note, some may object that experts and technology should not be allowed to substitute for juries' and judges' roles in assessing such things as competence and veracity. Or finally, maybe although it is permissible for the accused to cite neuroscientific evidence in an attempt to exculpate themselves, it would not be right to force all suspects (and maybe even all witnesses) to undergo identical procedures so that the state can track down and convict a criminal (Aharoni et al. 2008:157).

This short section's message is that neuroscience is not a silver bullet. It might indeed one day help us to answer some of the criminal law's diverse responsibility questions, but there are also many limitations to what neuroscience can do for us.

\footnotetext{
24 ... Either because they destroyed that capacity (e.g. by drinking alcohol) or because they failed to develop it as per the second point of the previous paragraph...

25 Or maybe only the more dangerous invasive techniques like those which use electrode implants-i.e. ECoG and DBS - might deliver sufficiently high precision results and sufficient reliability.
} 


\section{Conclusion}

Is neuroscience relevant to criminal responsibility? In a way, I have argued that it is, and in surprisingly many ways, but I hesitate to state my position like this because doing so obscures two points which I would rather emphasize.

Firstly, neither neuroscience nor responsibility are as unified as that. A plethora of different techniques and technologies, each with their distinct abilities and drawbacks, lurks beneath the umbrella heading "neuroscience", and at least six different concepts legitimately answer to the name "responsibility". Thus, if we really wanted to answer this relevance question, then we would have to ask quite a few more sub-questions-i.e. one for each relationship between each kind of responsibility and each kind of neuroscience.

Secondly, to devise technological solutions, scientists and engineers need clearly stated problems, and as I have argued it is far from clear what problem is stated by the question "Is neuroscience relevant to criminal responsibility?" That is why in "Which Responsibility?" I distinguished six different senses of the term "responsibility", and why in "Relevance" I then expressed the criminal law's responsibility questions by using those six more precise responsibility concepts. My hope is that by stating the criminal law's questions as precisely as possible, neuroscientists will find in those questions tractable problems which the scientific method might stand a chance of being able to address. Thus, the second reason why I hesitate to state my position as the claim that neuroscience is relevant to criminal responsibility, is because this claim re-introduces that single, unitary and generic responsibility concept, and that in turn re-obscures the diversity and specificity of the sorts of problems that the criminal law attempts to address.

So, cautiously, I will now conclude that neuroscience is indeed relevant to criminal responsibility. But this way of stating my conclusion should not obscure that neither neuroscience nor criminal responsibility are as unified as that, and most importantly that the criminal law asks many different responsibility questions.

Open Access This article is distributed under the terms of the Creative Commons Attribution Noncommercial License which permits any noncommercial use, distribution, and reproduction in any medium, provided the original author(s) and source are credited.

\section{References}

Aharoni, E., Funk, C., et al. (2008). Can neurological evidence help courts assess criminal responsibility? Lessons from law and neuroscience. Annals of the New York Academy of Sciences, 1124, 145-160.

APA. (2004). Brief for the American Psychological Association, and the Missouri Psychological Association as amici curiae supporting respondent. Washington, DC, American Psychological Association: i-xii, 1-30.

Blakemore, S.-J., \& Choudhury, S. (2006). Brain development during puberty: State of the science. Developmental Science, 9(1), 11-14.

Bovens, M. (1998). Two concepts of responsibility. In The quest for responsibility: Accountability and citizenship in complex organisations (pp. 22-42). Cambridge, UK: Cambridge University Press.

Broughton, R., Billings, R., et al. (1994). Homicidal somnambulism: A case report. Sleep, 17(3), $253-264$.

Burns, J. M., \& Swerdlow, R. H. (2003). Right orbitogrontal tumor with pedophilia symptom and constructional apraxia sign. Archives of Neurology, 60, 437-440.

Calabresi, G. (1970). Goals and subgoals of accident law. In The costs of accidents: A legal and economic analysis (pp. 24-33). London, UK: Yale University Press.

Cane, P. (2002). The nature and functions of responsibility. In Responsibility in law and morality (pp. 29-63). Portland, Oregon: Hart Publishing.

Cane, P. (2004). Responsibility in law and morality: Book symposium, author's introduction. Australian Journal of Legal Philosophy, 29, 160-163. 
Cephos Corp. (2009). Cephos Corp home page. Retrieved 20090802, from http://www.cephoscorp.com/.

Clark County Prosecuting Attorney. (2004). Official record of the execution of Charles Laverne Singleton on January 6, 2004 8:06 p.m. by Lethal Injection in Arkansas. Retrieved 20090808, from http://www. clarkprosecutor.org/html/death/US/singleton887.htm.

Coukell, A. (2006). No more lies. Proto (Spring): 32-37.

Daubert v. Merrell Dow Pharmaceuticals, Inc., 509 U.S. 579 (1993).

Dawkins, R. (2006). Let's all stop beating Basil's car. Retrieved 20071202, from http://www.edge.org/ q2006/q06_9.html\#dawkins.

Douglas, T. (2008). Moral enhancement. Journal of Applied Philosophy, 25(3), 228-245.

Duff, R. A. (1998). Responsibility. In E. J. Craig (Ed.), Routledge encyclopedia of philosophy (Vol. 9, pp. 290-294). New York, NY, USA: Routledge.

Egan, E. A. (2007). Neuroimaging as evidence. The American Journal of Bioethics, 7, 62-63.

Farwell, L. A., \& Smith, S. S. (2001). Using brain MERMER testing to detect concealed knowledge despite efforts to conceal. Journal of Forensic Sciences, 46(1), 135-143.

Feinberg, J. (1970). Sua culpa. In Doing \& deserving: Essays in the theory of responsibility (pp. 187-221). Princeton, NJ: Princeton University Press.

Fischer, J. M., \& Ravizza, M. (1998). Responsibility and control: A theory of moral responsibility. Cambridge, UK: CUP.

Gazzaniga, M. S. (2005). The Ethical Brain. New York, NY: Dana Press.

Gazzaniga, M. S. (2006). Facts, fictions and the future of neuroethics. In J. Illes (Ed.), Neuroethics: Defining the issues in theory, practice, and policy (pp. 141-148). Oxford, UK: Oxford University Press.

Glannon, W. (2002). The mental basis of responsibility. UK: Ashgate Publishing Limited.

Gogtay, N., Giedd, J. N., et al. (2004). Dynamic mapping of human cortical development during childhood through early adulthood. Proceedings of the National Academy of Sciences of the United States of America, 101(21), 8174-8179.

Goodenough, O. R., \& Prehn, K. (2004). A neuroscientific approach to normative judgment in law and justice. In S. Zeki \& O. R. Goodenough (Eds.), Law \& the brain. New York: Oxford University Press.

Goodin, R. E. (1986). Responsibilities. Philosophical Quarterly, 36, 50-56.

Goodin, R. E. (1987). Apportioning responsibilities. Law and Philosophy, 6, 167-185.

Greene, J., \& Cohen, J. D. (2004). For the law, neuroscience changes nothing and everything. In S. Zeki \& O. Goodenough (Eds.), Law \& the brain (pp. 207-226). New York: Oxford University Press.

Greene, J., \& Haidt, J. (2002). How (and where) does moral judgment work? Trends in Cognitive Sciences, $6(12), 517-523$.

Haidt, J. (2001). The emotional dog and its rational tail: A social intuitionist approach to moral judgment. Psychological Review, 108(4), 814-834.

Hart, H. L. A. (1968). Postscript: Responsibility and retribution. In Punishment and responsibility (pp. 210237). Oxford, UK: Clarendon Press.

Haydon, G. (1978). On being responsible. The Philosophical Quarterly, 28(110), 46-57.

Jancin, B. (2008). Deep brain stimulation helps lift refractory OCD: Early data suggest that DBS is effective, but adjunctive therapy is indispensable. Clinical Psychiatry News. Retrieved 20090805, from http:// findarticles.com/p/articles/mi_hb4345/is_1_36/ai_n29406569/.

Jones, O. D. (2004). Law, evolution and the brain: Applications and open questions. In S. Zeki \& O. R. Goodenough (Eds.), Law \& the brain (pp. 57-75). New York: Oxford University Press.

Kolber, A. (2007). Pain detection and the privacy of subjective experience. American Journal of Law and Medicine, 33, 433-456.

Kolber, A. (2009). The subjective experience of punishment. Columbia Law Review, 109(1), 182-236.

Kutz, C. (2004). Responsibility. In J. Coleman \& S. Shapiro (Eds.), Jurisprudence and philosophy of law (pp. 548-587). Oxford, UK: Oxford University Press.

Lacey, N. (2007). Space, time and function: Intersecting principles of responsibility across the terrain of criminal justice. Criminal Law and Philosophy, 1(3), 233-250.

Latzer, B. (2003). Between madness and death: The medicate-to-execute controversy. Criminal Justice Ethics 22(2).

Maibom, H. L. (2008). The mad, the bad, and the psychopath. Neuroethics, 1(3), 167-184.

Meynen, G. (2009). Exploring the similarities and differences between medical assessments of competence and criminal responsibility. Medicine, Health Care and Philosophy, 12(4), 443-451.

Moll, J., Zahn, R., et al. (2005). The neural basis of human moral cognition. Nature Reviews Neuroscience, 6, 789-799.

Morse, S. J. (2004). Session 1: Neuroscience, brain, and behavior VI: Neuroscience and the Law, from http://www.bioethics.gov/transcripts/sep04/session1.html. 
Morse, S. J. (2006). Moral and legal responsibility and the new neuroscience. In J. Illes (Ed.), Neuroethics: Defining the issues in theory, practice, and policy (pp. 33-50). Oxford, UK: Oxford University Press.

No Lie MRI. (2009). No Lie MRI-Home Page. Retrieved 20090802, from http://noliemri.com/.

Perry, S. R. (2000). Loss, agency, and responsibility for outcomes: Three conceptions of corrective justice. In J. Feinberg \& J. Coleman (Eds.), Philosophy of law (6th ed., pp. 546-559). Belmont, CA, USA: Wadsworth/Thompson Learning.

Reimer, M. (2008). Psychopathy without (the language of) disorder. Neuroethics, 1(3), 185-198.

Rosen, J. (2007). The brain on the stand. The New York Times. Retrieved 20090624, from http://www. nytimes.com/2007/03/11/magazine/11Neurolaw.t.html.

Sapolsky, R. M. (2004). The frontal cortex and the criminal justice system. Philosophical Transactions of the Royal Society of London, 359, 1787-1796.

Scanlon, T. M. (1998). Responsibility. In What we owe to each other (pp. 248-294). USA: The Belknap Press of Harvard University Press.

Scanlon, T. M. (2008). The illusory appeal of double effect. In Moral dimensions: Permissibility, meaning, blame (pp. 8-36). Cambridge, MA: Harvard University Press.

Snead, O. C. (2008). Neuroimaging and capital punishment. The New Atlantis 19(Winter): 35-63.

Tancredi, L. R. (2005). The bad and the mad. In Hardwired behavior: What neuroscience reveals about morality (pp. 143-161). New York, NY: CUP.

Tovino, S. A. (2007). Functional neuroimaging and the law: Trends and directions for future scholarship. The American Journal of Bioethics, 7(9), 44-56.

United States of America, Plaintiff-appellee, v. Robert Lyons, Defendant-appellant, United States Court of Appeals, Fifth Circuit. 739 F.2d 994 (1984).

Vincent, N. (2006). Responsibility, compensation and accident law reform. Discipline of Philosophy, Faculty of Humanities and Social Sciences. Adelaide, University of Adelaide, Doctor of Philosophy.

Vincent, N. (2009a). Neuroimaging and responsibility assessments. Neuroethics. doi:10.1007/s12152-0089030-8.

Vincent, N. (2009b). Responsibility: Distinguishing virtue from capacity. Polish Journal of Philosophy, 3(1), 111-126.

Vincent, N. (2009c). What do you mean I should take responsibility for my own ill health? Journal of Applied Ethics and Philosophy, 1, 39-51.

Wallace, R. J. (2002). Précis of responsibility and the moral sentiments. Philosophy and Phenomenological Research, 64(3), 680-681.

Watson, G. (2004). Two faces of responsibility. In Agency and answerability (pp. 260-288). Oxford, UK: OUP.

Weisberg, D. S., Keil, F. C., et al. (2008). The seductive allure of neuroscience explanations. Journal of Cognitive Neuroscience, 20(3), 470-477.

Westen, P. (2008). Individualizing the reasonable person in criminal law. Criminal Law and Philosophy, 2(2), 137-162.

Williams, B. (1995). Voluntary acts and responsible agents. In Making sense of humanity (pp. 22-34). Cambridge, UK: Cambridge University Press.

Williams, G. (2008). Responsibility as a virtue. Ethical Theory and Moral Practice, 11(4), 455-470. 